\title{
POESIA, TÉCNICA E UTOPIA: UMA REFLEXÃO SOBRE AS POSSIBILIDADES DA POESIA EM NOSSOS DIAS
}

\section{Gláucia Vieira Machado*}

Resumo: Este trabalho apresenta a poesia como possibilidade de resistência à crise de percepção, agravada em nossos dias pelo superpovoamento do planeta e pela busca de crescimento econômico desenfreado. Mesmo diante do fim da utopia, alardeado vigorosamente no final do século XX, a poesia continua a expandir seus espaços de atuação e suas linguagens, configurando cenário paradoxal entre intenção e acaso, gerando projetos em podemos falar de uma intenSão, em que a técnica retoma o lugar de pesquisa artística, como anuncia sua raiz etimológica.

Palavras-chave: Poesia brasileira contemporânea. Utopia. Técnica. Intenção. Acaso.

A história da poesia confunde-se com a história do homem e suas indagações sobre a vida e a morte. Temos registros poéticos em várias linguagens, em diferentes épocas e lugares do mundo, em todas as classes sociais, em todas as línguas, e anteriores mesmo à língua escrita.

Os primeiros registros poéticos escritos conhecidos são $O s$ Livros dos Mortos. Enterrados nos sarcófagos dos antigos egípcios, tinham o objetivo de fornecer as instruções necessárias para garantir ao morto uma passagem tranquiila ao paraíso. Na cultura suméria, encontramos Gilgamesh, herói da epopéia ou mito que celebra uma grande amizade e nos fala de um homem em busca de superar a morte, que, para não morrer de verdade, conta-nos sua história em milhares de versos. Outro exemplo nos vem da Arábia, e é bastante conhecido: Sheerazade, a heroína das Mil e uma noites, que nos ensina a artimanha poética de narrar e viver.

Como se pode ver, a poesia está sempre presente, mas

* Doutora em Comunicação e Semiótica, pela Pontifícia Universidade Católica de São Paulo, professora e pesquisadora dos cursos de graduação e pós-graduação em Letras da Universidade Federal de Alagoas. 
continua a ser algo incomum, devido a seu caráter extraordinário. Podemos mesmo dizer, concordando com o verso do poeta baiano Waly Salomão, que "O EXTRAORDINÁRIO É A MORADA DO POETA".

A poesia exige olhos livres e disponibilidade para conhecer, porque ela é, antes de tudo, conhecimento. O poeta busca o conhecimento de si mesmo, de seu mundo, de suas possibilidades de linguagens. E o conhecimento poético, embora muitas vezes lúdico, é também trabalhoso. A produção de poemas se constitui a partir de um diálogo com a tradição poética e se desenvolve na pesquisa de técnicas e materiais.

Diferente de outras manifestações artísticas, que conseguem melhores espaços nos mercados em geral, a poesia não é um produto de consumo dos mais vendáveis. Diferente até mesmo da ficção convencional, que possui um enredo e se oferece a um tipo de fruição, de entretenimento que pode torná-la comercializável, a poesia apresenta-se como mais "difícil", porque exige uma atitude especial do leitor. Isso porque estamos falando aqui de poesia enquanto pesquisa de linguagem, arte de devotados especialistas que buscam refletir sobre sua relação com seu tempo, com o mundo.

\section{IntenSão}

O poeta está sempre envolvido com a escolha de técnicas e materiais. Técnica, do grego, technikós, relativo à arte, pelo latim technicu. Em diferentes acepções, o termo técnica refere-se às habilidades do artista em desenvolver suas apresentações, seja como poeta, escritor, pintor ou escultor, dançarino ou músico. É bastante curioso que etimologicamente o adjetivo técnico refira-se ao artístico. Curioso e importante pensar a poesia como trabalho técnico, mas de uma técnica combinada à intenção e ao acaso. O poético pode ser presumido quando percebemos um projeto de alguém realizado, quando sua intenção de inventar um objeto artístico é bem sucedida.

Mas o controle que o artista tem de sua técnica não é absoluto. Seu projeto define uma intenção, mas são fatores que escapam de seu controle que determinam a inșerção de sua arte no contexto. Podemos pensar, desse modo, em algo como IntenSão. Uma relação entre a técnica e o tempo, que faz a vida contingente escapar do controle do 
artista. IntenSão significa controle associado ao acaso, lugar extraordinário daqueles que dominam a técnica e sabem que isso não significa tudo. Na esfera da produção poética, a técnica está relacionada ao ritmo que configura a estrutura do texto, relação de recursos e possibilidades.

A poesia é uma forma de buscar conhecer e transmitir, pois, sem a transmissão, o conhecimento não se completa. Nesse sentido, poesia tem tudo a ver com ciência e política. Ao mesmo tempo em que pensamos no poeta como alguém especial, extraordinário, ele é também um cidadão, alguém inserido em um mundo de conflitos e tensões.

\section{A poesia pensa o mundo}

Para desenvolver esse raciocínio, podemos citar o filme $O$ ponto de mutação. Baseado na obra do físico austríaco Frijof Capra e valendo-se do belo cenário do castelo medieval construído no Mont Saint-Michel, na França, o filme é a conversa de três personagens muito especiais: um poeta, uma cientista e um político. Nele são investigadas as implicações e impactos de uma espécie de mudança de paradigmas, como havia previsto e estudado o físico Thomas Kuhn, há mais de 20 anos. O ponto de partida dessa investigação é a observação de que os principais problemas visíveis do século XX - ameaça nuclear, destruição do meio ambiente, desigualdades e exploração gritante entre Norte e Sul, preconceitos políticos e raciais, o terror são todos sintomas ou aspectos diversos do que, no fundo, não passa de uma única crise fundamental, que é uma crise de percepção, uma percepção distorcida baseada no individualismo e na falta de relação entre pessoas, coisas e eventos.

Essas atitudes, por mais que possam ser racionalizadas, mostram-se próximas de uma esquizofrenia suicida geral, diante das mazelas que têm feito a um mundo superpovoado e globalmente conectado.

$\mathrm{Na}$ fala de cada personagem do filme $O$ ponto de mutação podemos ver a grande inquietação que paira sobre nós, nos dias de hoje: falta de referências e total insegurança. O que mais chama atenção no filme, no entanto, é que, da conversa instigante no Mont Saint-Michel, o político, a cientista e o poeta saem diferentes. 
A poesia que perpassa a reflexão dos três personagens determina a possibilidade de mudança.

De fato, a poesia tem sido, cada vez mais, um trabalho de pesquisadores que se dedicam a pensar o mundo. Alguns poemas trazem sentidos legíveis isoladamente, mas no seu conjunto reforçam sempre uma idéia geral. O poeta trabalha as palavras, revigora seus sentidos ao aproximá-las umas das outras, ao recuperar a força de expressões que estavam adormecidas no esquecimento. O poeta torna mais belas algumas palavras e inventa outras. A obra poética sustenta, em seu conjunto, a possibilidade de vários elementos tensionados em torno de uma idéia.

\section{A educação dos sentidos}

Brincar com palavras é uma atitude que os poetas sempre compartilham. A própria memória do poeta não pode ser controlada e determinada a priori, pois sabemos que o surgimento de uma palavra no ato da criação ou produção poética é um momento não calculado de valorização de uma memória de vida ou memória de leitura. Não sabemos mesmo quando começa um livro, em que página de que livro lido ou experiência vivida começou aquele livro que lemos. Nem sabemos onde acaba um livro, um livro não tem fim, pois tampouco sabemos quando os leitores irão propor leituras, interpretações, sentidos, prolongando a obra para além dos desenhos na página.

O poeta americano Ezra Pound disse que quando a poesia se afasta da música ela perde muito de suas potencialidades. A tradição oral atravessa toda a história da poesia. Os salmos bíblicos, por exemplo, foram, primeiramente, cânticos, assim como são cantadas as invenções improvisadas dos rimadori, de Creta, na Grécia, ou o côco de roda, em Alagoas, no Brasil.

Técnica diz da intenção, de um método, de um caminho, que supõe uma direção, que no caso da poética não exclui nenhum dos sentidos. A complexidade do conhecimento científico, em nosso tempo, já nos ensinou que as rígidas classificações e os argumentos dogmáticos não se sustentam nem são adequados para explicar os fenômenos físicos, químicos ou biológicos. No campo dos estudos das linguagens, a questão é certamente tão complexa quanto nos demais. Mesmo porque qualquer conhecimento só é possível porque se 
estrutura como uma linguagem.

É por isso que técnica está sempre aliada ao acaso, como nos ensinou Mallarmé: "um lance de dados jamais abolirá o acaso". Stepháne Mallarmé, o ousado poeta que se tornou emblema de um novo tempo para a poesia, ao se apropriar da página branca e afirmar que tudo existia para acabar em literatura.

Poesia viva

Em tempos de grandes avanços tecnológicas e debates sobre o fim da Utopia, o poeta Augusto de Campos, um dos mais respeitados poetas brasileiros, um dos criadores da poesia concreta, escreveu um poema que traz Mallarmé como centro de uma importante discussão. O poema se chama tvgrama (tombeau de Mallarmé):

$$
\begin{aligned}
& a h t t t m a l l a r m e ́ \\
& t t t t t t t t t t \\
& \text { a c a r n ée } t r i s t e \\
& t t t t t t t t t t t \text {. } \\
& \text { e } \mathrm{n} \text { i n g u ém } t \text { e lê } \\
& t t t t t t t t t t \\
& \text { t u d o t } t e x \text { is } t e \\
& \mathrm{p} r \mathrm{a} a \mathrm{c} \text { a b a } r \text { e } \mathrm{t} v
\end{aligned}
$$

$O$ poema traduz fina ironia em sua forma de $t v$, anunciando a predominância da tecnologia eletrônica sobre o poético. Se de um lado vemos o poeta desiludido, de outro voltamos às noções de Mallarmé, de que tudo acaba em poesia. No desabafo do poeta, a poesia aparece para expressar sua desilusão.

Ezra Pound disse: "o poeta é a antena da raça".

Em um jogo de idéias e numa montagem a partir de uma foto do poeta russo Vladimir Maiakovski, o poeta brasileiro Philadelpho Menezes realizou um poema visual em que modifica a definição de Pound e diz:

"O poeta é a antena da praça". 
Ser a antena da praça significa, ao mesmo tempo, ser capaz de compreender e traduzir os anseios de seu tempo e projetá-los em um futuro que alimente seus sonhos.

É isso que faz o poema Autópsia das utopias, de Élson Froes, presente em diversos sites na internet. O poeta utilizou cores bastante expressivas como o azul, o vermelho e o amarelo para falar de utopia e de sonhos. Autópsia é uma palavra forte, que lembra morte, dissecação de cadáver, mas as cores de seu poema contrariam essa tendência de leitura. O que Elson parece nos mostrar é que se os sonhos nunca morrem e se alguns desfechos são indesejados, existe a possibilidade de um exame atento e de uma investida vigorosa naquilo que realmente queremos. Afinal, antes de tudo, autópsia é exame, avaliação. E o movimento do poema parece nos dizer desse processo.

Outro poeta que merece registro é o mineiro Marcelo Dolabela, que desde muito cedo se dedicou ao trabalho de criação e divulgação da poesia. Integrante da geração mimeógrafo, anterior ao computador, fazia seus livros em casa e os distribuia aos amigos ou enviava pelos correios, aos possíveis interessados. Marcelo Dolabela também fez arte postal e participou, com seus cartões, de mostras em diversos lugares do mundo. Sempre ligado à música, criou a banda de rock Divergência Socialista. Eles se apresentaram em diversos espetáculos, e grupos famosos hoje no Brasil têm integrantes que passaram pela Divergência. Somado a tudo isso, Marcelo criou diversos poemas objetos, como o HAI KAIXA, feito a partir do suporte caixinha de fósforos onde foram colocados poemas no formato Haikai. Recentemente, editou seu Letrolatria, uma caixa com poemas visuais recolhidos de sua produção desde os anos 70 e realizou um cd de poemas musicados em parceria com outros poetas mineiros. O cd recebeu o nome de Cacograma e pode ser considerado um manifesto de poesia e música contemporâneas. Um dos poemas desse trabalho recebeu o título de "Heiddeger's song". Trata-se de uma reflexão sobre a relação da poesia com a história, a memória, a utopia. A partir de uma referência controvertida ao pensador alemão Martin Heidegger, o poema canta os paradoxos dos sentidos poéticos. As metáforas apresentadas na canção revelam miragens do espanto humano diante das impossibilidades: restos de nuvens, escombros da história. "Heidegger's song" parece nos dizer que todos os mistérios são assuntos da poesia, não porque ela possa encontrar alguma 
solução, mas porque ela parte da consciência das ciladas que as palavras guardam.

Heidegger's song

palavras escritas
em restos de nuvens
transformam as letras
em pedras de sal
os ventos que vêm
sob os pés da memória
sopram as pétalas
$\quad$ do azul do caos
os anjos que olham
$\quad$ os escombros da história
vão além da lei
$\quad$ do bem e do mal
as palavras da tribo
$\quad$ o nome de Deus
o eterno carimbo
impresso no céu
como falar da verdade
na casa de Sheerazade?
como falar de pecado
na casa de enforcado?
como falar consciência
na casa da violência?
como falar pro poeta
de sua obra completa?
como falar de amor
no lar do torturador?
como falar de cultura
na casa da ditadura?
como falar de ruído
pra quem não tem mais ouvido?
como falar poesia
depois do fim da utopia?
O livro depois do livro


É preciso ainda lembrar o trabalho de uma artista que traduz a condição de poeta engajada na linguagem de seu tempo, o mundo digital. Giselle Beiguelman é autora do premiado $O$ Livro depois do Livro (1999). Entre seus trabalhos mais recentes, destacam-se: Wop Art, para telefones celulares (2001), elogiado pela imprensa nacional e internacional, e a criação de painéis eletrônicos interativos como Leste o Leste? e Egoscópio (2002).

Seu trabalho aparece em antologias importantes e obras de referência devotadas às artes digitais on line, como o Yale University Library Research Guide for Mass Media e Information Arts: Intersections of Art, Science, and Technology (S. Wilson, MIT Press, 2001). Gisele participa dos principais eventos da área, em museus e centros de novas mídias como ZKM, Fundación Telefonica, Smart Project Space e MECAD, entre outros congressos e simpósios internacionais.

A determinação do poeta em procurar novos abrigos para a poesia parece traduzir o movimento de resistência possível em nossos dias. E aqui concluo este ensaio, com outro poema de Cacograma, dessa vez de Ana Caetano:

A guerra acabou

a guerra acabou

nós ainda vemos o inimigo

o sonho acabou

nós ainda amamos o perigo

a história acabou

a memória ainda é um anjo antigo

o mundo acabou

o futuro ainda é um abrigo. 
DA POESIA EM NOSSOS DIAS

Referências

CAMPOS, Augusto de. Despoesia. São Paulo: Perspectiva, 1994.

DOLABELA, Marcelo. Letrolatria: poemas visuais (1975-1996). Belo Horizonte: Associação Cultural Pandora \& Edições Fahrenheit 451, 2000.

MALLARMÉ, Stéphane. Mallarmé. Traduções e estudos críticos de Augusto de Campos, Décio Pgnatari e Haroldo de Campos. São Paulo: Perspectiva, 1974.

MENEZES, Philadelpho. A crise do passado. São Paulo: Experimento, 1994.

MENEZES, Philadelpho. Philadelpho Menezes 81/82. São Paulo: Edições Aicais820, 1984.

POUND, Ezra. A arte da poesia: ensaios escolhidos. Tradução Heloisa Lima Dantas e José Paulo Paes. São Paulo: Cultrix, 1976.

POUND, Ezra. ABC da literatura. Tradução Augusto de Campos e José Paulo Paes. São Paulo: Cultrix, 1977.

SAILORMOON, Waly. Gigolô de bibelôs. São Paulo: Brasiliense, 1983.

$\mathrm{CD}$ :

DOLABELA, Marcelo et al. Poesia Cacograma. Belo Horizonte: Edições Fahrenheit 451; Câmara Mineira do Livro, Governo de Minas Gerais e Prefeitura de Belo Horizonte, 2001.

Filme:

Ponto de mutação. Direção: Bernt Capra. Estados Unidos, 1990. Distribuição: Europa Filmes.

Sites:

http://planeta.terra.com.br/arte/PopBox/visual.htm. http://www.desvirtual.com 